\title{
Minimally invasive strabismus surgery (MISS) for inferior obliquus recession
}

\author{
Daniel S. Mojon
}

Received: 1 July 2008 /Revised: 26 September 2008 / Accepted: 6 October 2008 / Published online: 29 October 2008

(C) The Author(s) 2008. This article is published with open access at Spingerlink.com

\begin{abstract}
Purpose To present a novel, minimally invasive strabismus surgery (MISS) technique for inferior obliquus recessions. Methods Graded MISS inferior obliquus recessions were performed in 20 eyes of 15 patients by applying two small conjunctival cuts, one at the insertion of inferior obliquus and another where the scleral anchoring of the muscle occurred.

Results The amount of recession was $12.2 \pm 2.3 \mathrm{~mm}$ (range 6 to $14 \mathrm{~mm}$ ). The vertical deviation, which was measured in $25^{\circ}$ of adduction, decreased from preoperatively $12.8^{\circ} \pm$ $5.6^{\circ}$ to $2.7^{\circ} \pm 2.2^{\circ}(p<0.0001)$ at 6 months. LogMAR visual acuity was preoperatively $-0.10 \pm 0.17$ and at 6 months $-0.14 \pm 0.22(p>0.1)$. In one eye $(2.5 \%)$ the two cuts had to be joined because of excessive bleeding. Binocular vision improved in eight patients, remained unchanged in six patients, and decreased from 30 to 60 arcsec in one patient $(p>0.1)$. Conjunctival and lid swelling were hardly visible on the first postoperative day in primary gaze position in 10/20 (50\%) of eyes. Five of the eyes $(25 \%)$ had mild and five $(25 \%)$ moderate visibility of surgery. One patient out of $15(7 \%)$ needed repeat surgery because of insufficient reduction of the sursoadduction within the first 6 months. The dose-effect relationship 6 months postoperatively for an accommoda-
\end{abstract}

Approval: This research followed the tenets of the Declaration of Helsinki. The president of the Ethical Committee of Kanton St. Gallen has approved the use of this new technique.

The author has no financial interests in the new technique.

D. S. Mojon $(\bowtie)$

Department of Strabismology \& Neuro-Ophthalmology,

and University of Bern,

Kantonsspital St. Gallen,

St. Gallen 9007, Switzerland tive near target at $25^{\circ}$ adduction was $0.83^{\circ} \pm 0.43^{\circ}$ per mm of recession.

Conclusions This study demonstrates that small-incision, minimal dissection inferior obliquus graded recessions are feasible and effective to improve ocular alignment in patients with strabismus sursoadductorius.

Keywords Strabismus surgery - Minimally invasive surgery - Minimally invasive strabismus surgery .

Conjunctival opening · Strabismus sursoadductorius .

Inferior obliquus recession

\section{Introduction}

The main indications for inferior obliquus recession, sometimes combined with a tuck of the superior obliquus, are inferior obliquus overaction and superior obliquus palsy. Usually, the conjunctiva is opened with one large cut, making it possible to visualize the inferior obliquus insertion and, if a graded recession technique is used, the site where the muscle will be reattached to the sclera [1]. The large cut induces considerable anatomical disruption, especially for larger amounts of recession, and usually does not allow an optimal visualization of the insertion, which is more posterior to the opening.

In many surgical disciplines, keyhole techniques have been introduced, making it possible to reduce tissue traumatism, postoperative patient discomfort, hospital stay, working disability, and the economic impact of operations $[2,3]$. Ophthalmologists also have introduced many keyhole or otherwise minimally invasive procedures, e.g. for cataracts [4], for glaucoma [5, 6], for vitreoretinal surgery [7, 8], for the lacrimal system [9], and for lids [10]. In rectus muscle strabismus surgery, several variants to 
reduce the conjunctival incision size have been published after Harms published his widely used limbal approach [11]. Smaller conjunctival openings, especially if placed away from the limbus, will induce less tissue disruption and less postoperative discomfort. Probably, they also reduce the risk for an anterior segment ischemia [12]. A nice alternative to a limbal opening, which can be used in patients with elastic conjunctiva, is Parks' fornix opening [13]. Another alternative for rectus muscle displacements, which further reduces anatomical disruption and can be used also in patients with inelastic conjunctiva, uses two keyhole openings placed near to the muscle insertion [14]. The term minimally invasive strabismus surgery (MISS) was created for strabismus surgeries minimizing the conjunctival opening size and anatomical disruption by placing several keyhole openings where really necessary [14]. Patients operated with a MISS recession/plication technique had better visual acuities and less lid swelling the day after surgery compared to a group of patients operated with the usual limbal approach, indicating that such techniques may be superior in the direct postoperative period [14].

This study describes how the MISS principle can be used for inferior obliquus recessions using two minimal cuts, one placed where the muscle needs to be detached and another where the scleral refixation occurs. This access and tissue dissection technique minimizes tissue disruption and allows optimal visualization of the muscle desinsertion, since one cut is placed directly over the insertion site.

\section{Patients and methods}

This study presents the results of the first 20 consecutive eyes from 15 patients operated on with a MISS inferior obliquus recession technique at Kantonsspital St. Gallen. The investigation followed the ethical standards laid down in the 1964 Declaration of Helsinki. The president of the Ethical Committee of Kanton St. Gallen has approved the use of this new technique.

Patients

Inclusion criteria All consecutive patients needing inferior obliquus recessions operated on by the author between December 2006 und December 2007 were included. In the same time period, a proportion of inferior oblique recessions was performed by another surgeon in a conventional matter. The author is not aware that this has introduced bias, since surgeries were distributed between the two surgeons by availability in the operating theatre. Usually, patients with fourth nerve palsies were treated with a superior oblique tuck or combined inferior oblique reces- sion and superior oblique tuck. Fourth nerve palsies with rather comitant and not too large angles in adduction were treated with isolated inferior rectus recessions.

Exclusion criteria Patients necessitating simultaneous superior obliquus or vertical rectus surgery or whose inferior oblique muscle was already previously operated on. All patients had at least one complete orthoptic examination 5 days before the surgical procedure, on the first postoperative day, and after 6 months (range 5-7 months) at the Department of Strabismology and Neuro-Ophthalmology, Kantonsspital, St. Gallen, Switzerland. The following parameters were registered: deviation in primary position and in $25^{\circ}$ of adduction for a near target, head posture, field of binocular single vision, motility, stereovision, visual acuity, refraction, lid and conjunctival swelling and redness, and number and types of complications. Abnormal head posture was estimated while the patient was looking at an accommodative target at $33 \mathrm{~cm}$. Binocular single vision was measured using Bagolini's striated glasses and, if possible, using Harms' tangent screen [15]. Stereovision was measured in an ordinal scale with following tests: twopencil test, Titmus stereotest, and TNO-test. For the two plate tests, values were registered in arcsec. For analysis, each patient was categorized as "improved", "same", or "worse". Since many patients were too young to allow an adequate measurement while fixating at a distance target, only deviations while looking at an accommodative target in $33 \mathrm{~cm}$ were included. Of 17 patients eligible for the study, $15(88 \%)$ could be included. Two patients were excluded since they did not come back for the 6-month follow-up visit. None of them had an intraoperative or immediate postoperative complication. Conjunctival and lid swelling was determined on the first postoperative day using a previously used grading system developed for horizontal rectus muscle surgery [16]. The scale of conjunctival and lid swelling and injection ranges from 0 to 3 ( 0 meaning absent, 1 mild, 2 moderate, 3 strong).

\section{Methods}

Surgical technique for MISS inferior obliquus recession Surgery is performed using the operating microscope under general anesthesia. All surgical steps can be performed without an assistant. The amount of recession corresponded to the vertical deviation determined in $25^{\circ}$ of adduction. For each millimeter of recession an anteralization of $1 / 3$ of a millimeter was performed, which makes it possible to reattach the anterior border along the physiologic course of the muscle. Preoperatively, no eye drops were given. Directly before surgery, the eyelids and the skin surrounding the operative site were disinfected with Betadine ${ }^{\circledR}$ 
Fig. 1 Schematic representation of the surgical technique for MISS inferior obliquus recession. After applying a limbal traction suture to expose the temporal inferior quadrant of the eye globe, a radial cut is performed over the insertion of the inferior obliquus muscle (a). A second cut is applied where later the reinsertion will be performed. With blunt Wescott scissors the inferior obliquus insertion is separated from the surrounding tissue (b). Then, the insertion is completely detached (c). Now, one single suture is applied to the anterior third of the detached muscle insertion (d). Afterwards, a blunt cannula is passed through the second cut, the reinsertion site opening, and advanced in order to get out through the first cut (e). The needle is gently inserted in the cannula until it is fixed (f). Now, the cannula is retracted (g) and the scleral fixation is performed (h). The surgical procedure is finished by applying single sutures to each of the two small cuts (i). If a better visualization is needed, the two small cuts can be joined to form one large opening $(\mathbf{j})$

(Iodum $10 \mathrm{mg}$ ut povidonum iodinatum excip. ad solute. pro $1 \mathrm{ml})$. The conjunctiva was not rinsed. A limbal traction suture (Silkam ${ }^{\circledR}$ 6-0 or Safil ${ }^{\circledR}$ 6-0 BV-1) is applied in order to expose the temporal inferior quadrant of the eye globe. During surgery, a direct contact of the traction suture with the cornea has to be avoided. A $4 \mathrm{~mm}$ radial cut is performed over the insertion of the inferior obliquus muscle (Fig. 1a). The anterior margin of the cut is $1 \mathrm{~mm}$ anterior of the tendon insertion. In patients with reduced elasticity of the conjuntival tissue, a slightly larger opening will be needed. A second cut is applied where later the reinsertion will be performed. If the reattachment will be next to the lateral border of the inferior rectus muscle, the muscle itself will help as a landmark. If a graded recession of a certain amount is planned, the place is marked using a measure caliper. With blunt Wescott scissors, the inferior obliquus inseration is separated from the surrounding tissue (Fig. 1b). Then, using the same scissors, the insertion is completely detached (Fig. 1c). Now, one single suture (Vicryl ${ }^{\circledR}$ 7-0 GS-8) is applied to the anterior third of the detached muscle insertion (Fig. 1d). In this patient series, only the anterior border was reinserted to the sclera, and therefore no second posterior suture was used. Afterwards, a blunt cannula (Hurricain Medical, 20G x 1 in. SubTenon's Anaesthesia Cannula) is passed through the second cut, the reinsertion site opening, and advanced in order to get out through the first cut (Fig. 1e). The needle is gently inserted in the cannula until it is fixed (Fig. 1f). Now, the cannula is retracted (Fig. 1g). After withdrawal of the needles from the cannula, the scleral fixation is performed (Fig. 1h). After having controlled that all posterior fibers of the inferior obliquus insertion have been properly cut, the surgical procedure is finished by applying single sutures (Vicryl ${ }^{\circledR}$ Rapid 8-0 GS-8) to each of the two small cuts (Fig. 1i). At the end of surgery, TobraDex ${ }^{\circledR}$ ointment (1 mg dexamethasone and $3 \mathrm{mg}$ tobramycin per g, $0.5 \%$ chlorobutanol) or Maxitrol ${ }^{\circledR}$ ointment (polymyxin B sulphate 6,000 units, neomycin sulphate 3,500 units, dexamethasone
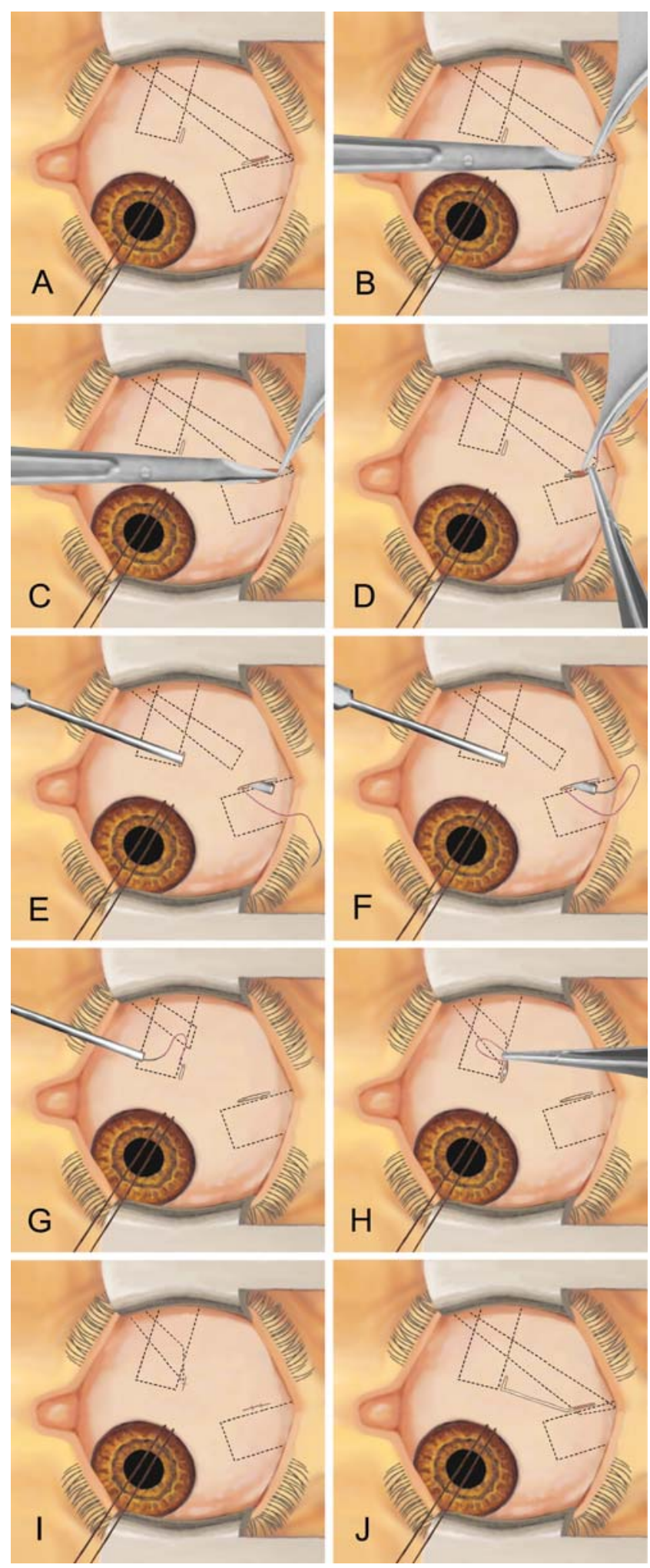

$1.0 \mathrm{mg}$, methylparaben $0.05 \%$, and propylparaben $0.01 \%$ ) was applied. There was no need for an eye patch. For the first 2 weeks after surgery the following treatment was prescribed: TobraDex ${ }^{\circledR}$ suspension $(1 \mathrm{mg}$ dexamethasone and $3 \mathrm{mg}$ tobramycin per $\mathrm{ml}, 0.01 \%$ benzalkonium 
chloride) t.i.d. and TobraDex ${ }^{\circledR}$ ointment in the evening or Maxitrol $^{\circledR}$ suspension (polymyxin B sulphate 6,000 units, neomycin sulphate 3,500 units, dexamethasone $1.0 \mathrm{mg}$, and benzalkonium chloride $0.004 \%$ ) t.i.d. and Maxitrol ${ }^{\circledR}$ ointment in the evening. If during minimally invasive surgery the operating site needs to be better visualized, e.g. if excessive bleeding occurs, which cannot be stopped with cautery through the small cuts, the two openings can be joined (Fig. 1J).

\section{Statistical methods}

Comparison of paired variables was performed using the Wilcoxon signed-rank test. Frequencies were compared with the Chi-square test.

\section{Results}

The mean age at the time of surgery of the 15 patients included in this study was 12 years (median 9, range 2-42). Three patients were younger than 6 years, five between 6 and 12 , three older than 12 but younger than 18 , and four adults. Eleven (55\%) of the operated eyes were right eyes, and nine left eyes $(45 \%)$. One patient (one eye) needed surgery because of fourth nerve palsy, 14 patients ( 23 eyes) because of strabismus sursoadductorius. The amount of recession was $12.2 \pm 2.3 \mathrm{~mm}$ (range $6-14 \mathrm{~mm}$ ). The vertical deviation, which was measured in $25^{\circ}$ of adduction, decreased from preoperatively $12.8^{\circ} \pm 5.6^{\circ}$ to $2.7^{\circ} \pm 2.2^{\circ} \quad(p<0.0001)$ at 6 months. In five children an exact measurement was impossible, and therefore upshot was estimated from corneal reflexes. Four of them did not show any upshoot at month 6; one who had a very strong upshoot still had a strong upshoot. No patient experienced diplopia or had an abnormal head posture at 6 months. Binocular vision improved in eight patients, remained unchanged in six patients, and decreased from 30 to 60 arcsec in one patient $(p>0.1)$. Motility was normal in all patients before and after surgery. $\log$ MAR visual acuity was preoperatively $-0.10 \pm$ 0.17 and at 6 months $-0.14 \pm 0.22(p>0.1)$. The following changes in astigmatism were found at month 6 : twice 0.25 dpt less, once $0.75 \mathrm{dpt}$ less, once $0.25 \mathrm{dpt}$ more, and once $0.5 \mathrm{dpt}$ more. Conjunctival and lid swelling was hardly visible on the first postoperative day in primary gaze position in $10 / 20(50 \%)$ of eyes. Five eyes $(25 \%)$ had mild and five $(25 \%)$ moderate visibility of surgery. Figure 2 shows an eye with hardly visible surgery on the first postoperative day. In one eye $(2.5 \%)$, the cut had to be increased because of excessive bleeding that could not be stopped through the small cut at the reinsertion site. After enlarging the cut, the bleeding could be easily stopped. One patient out of $15(7 \%)$ needed repeat surgery because of insufficient reduction of the sursoadduction within the first 6 months. The dose-effect relationship 6 months postoperatively for an accommodative near target at $25^{\circ}$ adduction was $0.83^{\circ} \pm 0.43^{\circ}$ per $\mathrm{mm}$ of recession.

\section{Discussion}

Many recent advances in eye surgery are a result of the introduction of minimally invasive techniques. Usually, a reduction of anatomical disruption will result in shorter operating times, less postoperative discomfort, shorter hospital stays, a decrease in working disability, and more ease to perform repeat surgery. One possibility to induce less tissue disruption is to reduce the opening size through which surgery is performed. However, this might increase the risk for complications due to restricted access to the operating site.

In this study, a minimally invasive obliquus graded recession technique and their results have been presented. Recession is performed through two small radial cuts, one placed at the obliquus insertion site and one where the muscle is reinserted to the sclera (Fig. 1). The advantage of this new technique is a better visualization of the desinsertion of the muscle, since one opening is placed exactly where the muscle is detached. Additionally, anatomical disruption is minimized, since the conjunctiva is only opened at the desinsertion and reinsertion site. If the surgeon needs a better visibility of the operative site, the small cuts can be enlarged or even joined (Fig. 1j). In this patient series, there was need for that in one eye (5\%). The whole surgical procedure can be performed with the same instruments used for standard, limbal approach apart from use of a blunt cannula. There is no need for an assistant. Despite a restricted conjunctival opening, the MISS technique made it possible to adequately perform surgery.

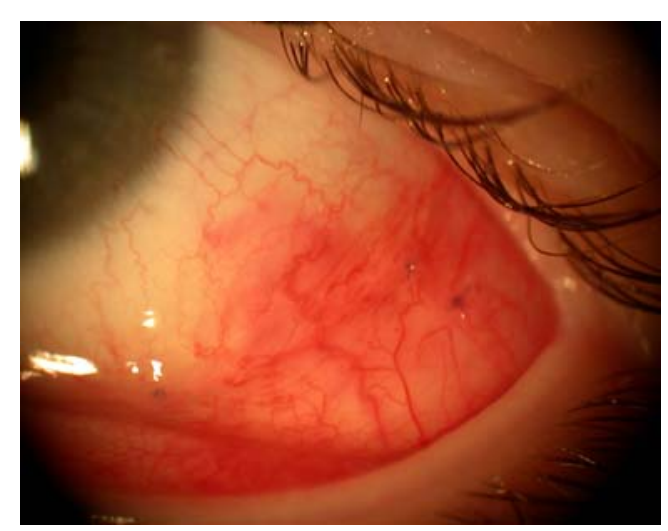

Fig. 2 Photographs of a 15-year-old girl with strabismus sursoadductorius 24 hours after a $13 \mathrm{~mm}$ recession of the left inferior obliquus muscle. The conjunctiva has been closed with two single sutures at the original insertion site and with one single suture where the muscle has been reattached to the sclera 
The author didn't experience a learning curve while doing these first 20 cases. One reason could be that he was already using a similar technique for rectus muscle transposition surgery before starting with this type of operation. Immediately postoperatively, lid and conjunctival swelling and redness could be minimized in many cases (Fig. 2). There was no need for eye patching or additional lubrification of the operated eyes. At 6 months, all outcomes were satisfactory apart from one patient needing repeat surgery because of a still strong sursoadduction. The dose-effect relationship after 6 months for an accommodative near target at $25^{\circ}$ adduction was $0.83^{\circ} \pm 0.43^{\circ}$ per mm of recession. This value is within the confidence interval of studies using a similar recession technique [17]. Six months postoperatively, only a minimal cicatrisation was found along the openings, which did not hinder free movement of the conjunctiva over the sclera and muscle. It could be hypothesized that this minimal scarring might facilitate reoperations. The small number of patients operated with this new technique does not make it possible to determine if some rare complications might occur more frequently compared to techniques using larger openings. However, this seems unlikely, since the two cuts allow optimal visualization for the two critical steps of surgery, namely muscle desinsertion and scleral reattachment. The doseresponse relationship of $0.83^{\circ} \pm 0.43^{\circ}$ per mm of recession should be used with caution because of the small number of patients included in this study.

Although these first results are promising, definitive superiority of MISS for graded obliquus inferior recession has to be proven by additional reports including larger number of patients.

Surgeons who would like to start with MISS inferior oblique recessions should start doing surgery in patients between 10 and 30 years of age. In younger patients, Tenon might hinder a good view of the operating site, and in older patients inelastic conjunctiva might easily tear.

In summary, the technique and the results of a new access technique for graded inferior obliquus recession have been presented, which seems to be safe and more rational than previous openings. A placement of the incision in the regions, which need to be visualized to perform surgery, makes it possible to minimize the total opening size and the anatomical disruption. However, it's not advisable that inexperienced surgeons start performing MISS before having gained enough experience with open surgery.

Acknowledgements I would like to thank the orthoptists Andrea Kunz and Elisabeth Türk for data collection.
Open Access This article is distributed under the terms of the Creative Commons Attribution Noncommercial License which permits any noncommercial use, distribution, and reproduction in any medium, provided the original author(s) and source are credited.

\section{References}

1. Ehrt O, Bekl Y, Boergen KP (2002) Effect of inferior oblique recession in strabismus sursoadductorius. Strabismus 10:63-68, doi:10.1076/stra.10.2.63.8138

2. Darzi A, Mackay S (2002) Recent advances in minimal access surgery. BMJ 324:31-34, doi:10.1136/bmj.324.7328.31

3. Harrell AG, Heniford BT (2005) Minimally invasive abdominal surgery: lux et veritas past, present, and future. Am J Surg 190:239-243, doi:10.1016/j.amjsurg.2005.05.019

4. Agapitos PJ (1991) Cataract surgical techniques. Curr Opin Ophthalmol 2:16-27, doi:10.1097/00055735-199102000-00003

5. Lüke C, Dietlein TS, Lüke M et al (2008) A prospective trial of phaco-trabeculectomy combined with deep sclerectomy versus phaco-trabeculectomy. Graefes Arch Clin Exp Ophthalmol 246:1163-1168, doi:10.1007/s00417-008-0821-8

6. Traverso CE, De Feo F, Messas-Kaplan A et al (2005) Long term effect on IOP of a stainless steel glaucoma drainage implant (ExPRESS) in combined surgery with phacoemulsification. $\mathrm{Br} \mathrm{J}$ Ophthalmol 89:425-429, doi:10.1136/bjo.2004.058032

7. Fang SY, Deboer CM, Humayun MS (2008) Performance analysis of new-generation vitreous cutter. Graefes Arch Clin Exp Ophthalmol 246:61-67, doi:10.1007/s00417-007-0672-8

8. Kreissig I (2003) View 1: minimal segmental buckling without drainage. Br J Ophthalmol 87:782-784, doi:10.1136/bjo.87.6.782-a

9. Watkins LM, Janfaza P, Rubin PA (2003) The evolution of endonasal dacryocystorhinostomy. Surv Ophthalmol 48:73-84, doi:10.1016/S0039-6257(02)00397-1

10. Frueh BR, Musch DC, McDonald HM (2004) Efficacy and efficiency of a small-incision, minimal dissection procedure versus a traditional approach for correcting aponeurotic ptosis. Ophthalmology 111:2158-2163, doi:10.1016/j.ophtha.2004. 07.019

11. Harms H (1949) Über Muskelvorlagerung. Klin Monatsbl Augenheilkd 115:319-324

12. Kushner BJ (2007) Comparison of a new, minimally invasive strabismus surgery technique with the usual limbal approach for rectus muscle recession and plication. Br J Ophthalmol 91:5, doi:10.1136/bjo.2006.108381

13. Parks MP (1968) Fornix incision for horizontal rectus muscle surgery. Am J Ophthalmol 65:907-915

14. Mojon DS (2007) Comparison of a new, minimally invasive strabismus surgery technique with the usual limbal approach for rectus muscle recession and plication. Br J Ophthalmol 91:76-82, doi:10.1136/bjo.2006.105353

15. Pfenninger L, Landau K, Bergamin O (2006) Comparison of Harms tangent screen and search coil recordings in patients with trochlear nerve palsy. Vision Res 46:1404-1410, doi:10.1016/j.visres.2005.06.026

16. Schwarwey K, Gräf M, Becker R, Kaufmann H (2000) Healing process and complications after eye muscle surgery. Ophthalmologe 97:22-26, doi:10.1007/s003470050005

17. Metten M, Link H, Staubach F et al (2008) Dose-response relationship in inferior oblique muscle recession. Graefes Arch Clin Exp Ophthalmol 246:593-598, doi:10.1007/s00417-007-0763-6 